\section{BRITISH MADE AND HALF THE PRICE OF OTHER LASERS}

Quicklase have launched a 'recession free' laser, the dentaLase. It is British made, calibrated and serviced here in the UK and is designed to appeal to and be obtainable by all dental practices. It comes fully loaded with features and eight programmable pre-sets, including troughing, gum recontouring, perio, endo and teeth whitening. There is a colour coded screen for ease of use and built in fibre caddy to protect the fibre. In addition there is a wall mounted bracket option.

The dentaLase Laser is half the price of its competitors.

For more information call 01227780009 or visit www.Quicklase.com.

\section{A 'WOW' FEELING WITHOUT SENSITIVITY}

Church \& Dwight UK Ltd, the makers of Arm \&t Hammer toothpaste, have relaunched Enamel Care Sensitive toothpaste with an improved formula that fixes the cause of sensitive teeth and is clinically proven to provide pain relief for up to 16 weeks. With $73 \%$ of adults in Britain suffering from sensitive

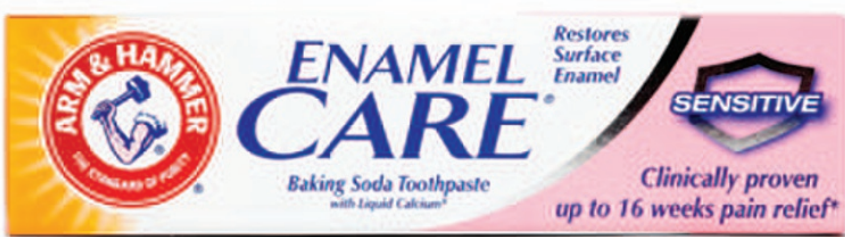

\section{BRING SUPPORT TO BRUXISM SUFFERERS}

Bruxism Awareness Week takes place on 22-28 October 2012 and provides a vital opportunity for both patients and dental professionals to learn lessons about the condition, according to the dental splint professionals at S4S.

The condition is believed to affect between $8-10 \%$ of the UK population. Characterised by teeth grinding and clenching, bruxism causes migraines, jaw pain and poor sleep quality for sufferers. It can often go undiagnosed for years.

A number of proven treatments, such as the NTI-tss occlusal splint system from S4S, are now available to offer hope for sufferers.

Bruxism Awareness Week will see initiatives to raise awareness of the condition, and to help sufferers understand that their suffering can be brought to an end with the right help.

The event will include a series of seminars and promotional events to draw attention to the scale of the suffering brought about by bruxism.

For further details on bruxism, its effects, management and dental splint technology, visit www.s4sdental.com/.

\section{LOSS ADJUSTMENT WITHIN HOURS}

DAS has launched Loss Assist to provide dentists with their own loss adjustor to process their side of the claim should a major event such as a fire or flood occur.

Events such as these are covered under business interruption and material damage insurance policies and, in the event of a claim under these policies, insurance companies will appoint their own loss adjustors to assess the damage and extent of the claim from their perspective.

Loss Assist gives dentists the support of a dedicated loss adjustor within 24 hours of reporting a claim, right through to settlement by their insurer.

Advantages include a yearround 24 hour loss adjustor response; claims submission, negotiation and administration; and up to $£ 100,000$ in expert fees to support a claim.

The policy usually costs around 5\% of the existing commercial insurance premium. www.das.co.uk 